\title{
Synthesis of Ganglioside GD3 and its Comparison with Bovine GD3 with Regard to Oligodendrocyte Apoptosis Mitochondrial Damage
}

\author{
Julio C. Castro-Palomino, ${ }^{[a]}$ Bernadett Simon, ${ }^{[b]}$ Oliver Speer, ${ }^{[c]}$ Marcel Leist, ${ }^{*[b]}$ and \\ Richard R. Schmidt* $*$ a]
}

\begin{abstract}
Dehydroneuraminic acid derivative $\mathbf{5}$ was transformed in five efficient steps into sialyl donor $\mathbf{2}$, which has a phenylthio group on the $\beta$-side of the 3-position for anchimeric assistance and a diethyl phosphite residue as leaving group at the anomeric carbon. The known GM3 intermediate $\mathbf{1 0}$ was transformed into the $4 \mathrm{~b}, 4 \mathrm{c}, 8 \mathrm{c}-O$-unprotected acceptor $\mathbf{3}$, which was then allowed to react with 2 by using TMSOTf as
\end{abstract}

catalyst and acetonitrile as solvent to afford the desired tetrasaccharide 12, which has an $\alpha(2-8)$-linkage between two neuraminic acid residues. Removal of the phenylthio group gave intermediate $\mathbf{1 3}$, which was transformed into $O$ -

Keywords: anchimeric assistance . apoptosis • gangliosides • glycolipids $\cdot$ synthesis design tetraosyl trichloroacetimidate $\mathbf{1 6}$ as glycosyl donor. Application of the azidosphingosine glycosylation procedure furnished GD3 (1) in high overall yield. Comparison of synthetic GD3 with bovine-brain-derived GD3 showed that there were similar effects in GD3-triggered uncoupling of mitochondrial respiration and in induction of apoptosis in oligodendrocytes.

\section{Introduction}

Gangliosides have attracted a lot of attention because of their manifold biological roles. ${ }^{[1]}$ Disialoganglioside GD3 (Scheme 1, 1), and particularly its $9 \mathrm{~d}-O$-acetyl derivative, were found to be human melanoma-associated antigens. ${ }^{[2,3]}$ Recently, endogenously formed GD3 has been implicated in intracellular signalling with proapoptotic function. ${ }^{[4]}$ Moreover, extracellular GD3 was reported to induce apoptotic cell death in a variety of cell types, most likely by triggering permeability transition. Under neuroinflammatory conditions, GD3 may be formed by microglial cells and is found at increased concentrations in cerebral liquor. Thus, the ganglioside may contribute to selective oligodendrocyte loss in conditions such as multiple sclerosis, and examination of the cell pathways triggered by GD3 may reveal new targets for pharmacological intervention in degenerative diseases. ${ }^{[7]}$

[a] Prof. Dr. R. R. Schmidt, J. C. Castro-Palomino

Fachbereich Chemie, Universität Konstanz

Fach M725, 78457 Konstanz (Germany)

Fax: (+49)7531-88-3135

E-mail: richard.schmidt@uni-konstanz.de

[b] Priv.-Doz. Dr. M. Leist, B. Simon

Fachbereich Biologie, Universität Konstanz

Fach X911, 78457 Konstanz (Germany)

E-mail: marcel.leist@uni-konstanz.de

[c] O. Speer

Institute of Cell Biology, ETH-Hoenggerberg 8093 Zürich (Switzerland)
However, these investigations were hampered by the varying biological activity and undefined nature of different lots of commercially available natural GD3 isolates. Therefore, we initiated a chemical synthesis of GD3 and compared the proapoptotic effect of the synthetic ganglioside with those of purified bovine-brain fractions.

\section{Results and Discussion}

Synthesis of GD3: The chemical synthesis of GD3 has to overcome the difficult formation of the $\alpha(2-8)$-linkage between two $\mathrm{N}$-acetyl neuraminic acid (Neu5Ac) residues. ${ }^{[8]}$ This task has been successfully addressed by a few research groups. ${ }^{[8-14]}$ The rather low reactivity observed for the 8-hydroxy group of variously protected neuraminic acid acceptors and the tendency of the sialyl donors towards $\beta$ linkage formation and/or towards competing 2,3-dehydroneuraminic acid generation led to the conclusion that for successful $\alpha(2-8)$-linkage formation the activated sialyl donor requires anchimeric assistance in order to shield the $\beta$-face and to provide stabilisation of the incipient carbonium ion intermediate. Hence, phenylthio ${ }^{[9-11]}$ and the phenylthiocarbonyloxy ${ }^{[8,13,14]}$ groups were introduced on the $\beta$-side. Benzyl and acetyl groups were chosen for hydroxy-group protection, and bromo, chloro, phosphite and ethylthio groups were selected as leaving groups at the 2-position. We report here on the usefulness of sialyl donor 2 (Scheme 1), which possesses an anchimerically assisting 3-phenylthio group on 


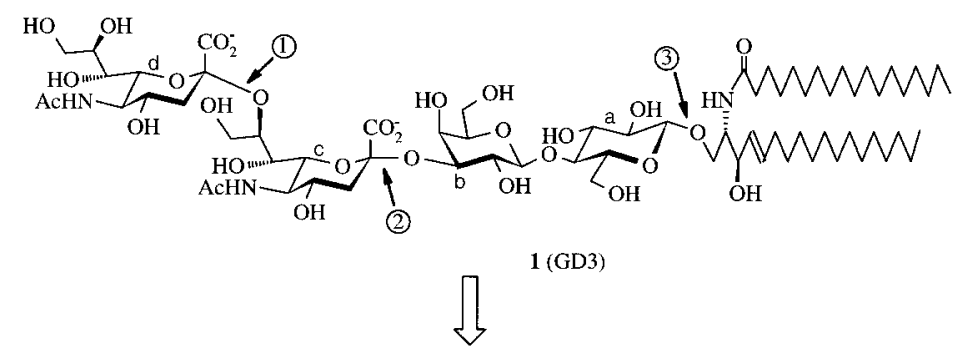

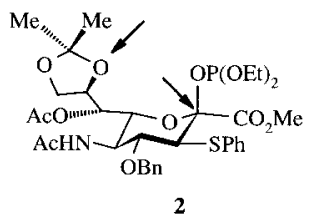

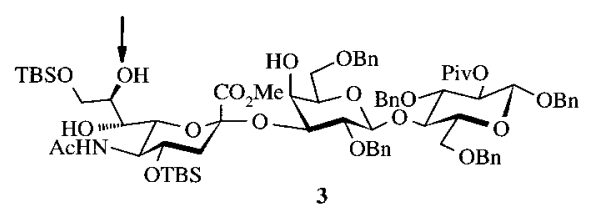

$\mathrm{HO}_{2} \mathrm{C}-\mathrm{C}_{17} \mathrm{H}_{35}$

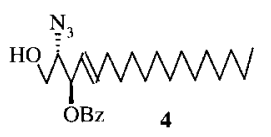

Scheme 1.

the $\beta$-side and diethyl phosphite as leaving group, which requires only catalytic amounts of acid for activation. Thus, we combined the anchimeric assistance as introduced by Ogawa et al. ${ }^{[9]}$ and the activation of the anomeric leaving group by acid catalysis as introduced by us. ${ }^{[15]}$ The protectivegroup pattern of $\mathbf{2}$ was selected in order to permit transformation of the product into an 8 - $O$-acceptor for further chain extension with $\mathbf{2}$.

The retrosynthesis in Scheme 1 shows that besides 2 (disconnection at (1)), a GM3 trisaccharide building block $\mathbf{3}$ is required which should be available from a lactose acceptor and a conventional sialyl donor (disconnection at (2)) following literature precedents. ${ }^{[15]}$ The disconnection at (3) liberates the ceramide moiety which can be attached through the azidosphingosine glycosylation procedure ${ }^{[16]}$ which calls for the known 3-O-benzoyl-azidosphingosine ${ }^{[17]}$ and stearic acid.

For the synthesis of sialyl donor 2 , the known 2,3dehydroneuraminic acid ester $\mathbf{5}^{[18]}$ (Scheme 2) was treated with acetone in the presence of trifluoromethanesulfonic acid
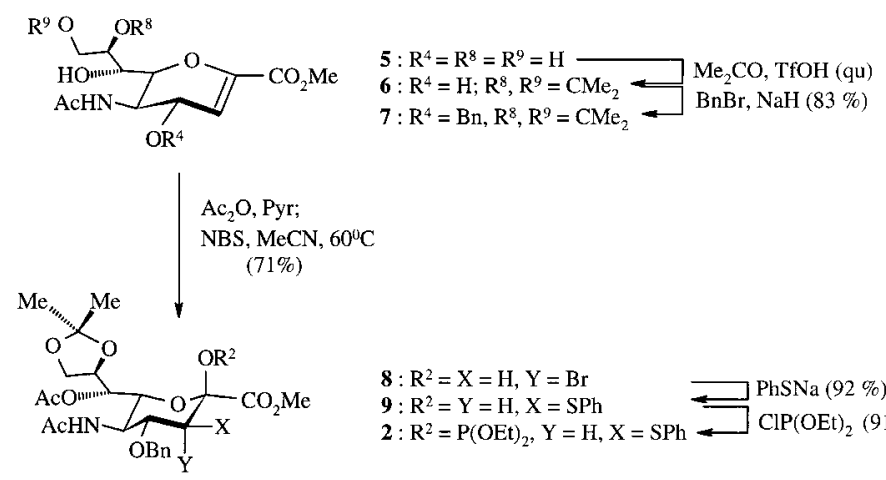

8: $\mathrm{R}^{2}=\mathrm{X}=\mathrm{H}, \mathrm{Y}=\mathrm{Br}$
9: $\mathrm{R}^{2}=\mathrm{Y}=\mathrm{H}, \mathrm{X}=\mathrm{SPh}$
$\mathbf{2}: \mathrm{R}^{2}=\mathrm{P}(\mathrm{OEt})_{2}, \mathrm{Y}=\mathrm{H}, \mathrm{X}=\mathrm{SPh} \longrightarrow \mathrm{PhSNa}(92 \%)$
$\mathrm{ClP}(\mathrm{OEt})_{2}(91 \%)$

Scheme 2 .

$(\mathrm{TfOH})$ as catalyst to furnish exclusively the 8,9- $O$-isopropylidene derivative 6. $^{[14]}$ Benzylation of $\mathbf{6}$ with benzyl bromide and sodium hydride as base in DMF afforded the 4- $O$-benzylprotected derivative 7 in high yield. For the $\alpha$-side-selective bromine addition, 7 was first treated with acetic anhydride in pyridine and then with $\mathrm{N}$-bromo-succinimide in acetonitrile at $60{ }^{\circ} \mathrm{C}$ to afford the desired 3-bromo derivative 8. Treatment with sodium thiophenolate in THF gave, with inversion of configuration, the 3-phenylthio derivative 9; the structural assignment of which was confirmed by the ${ }^{1} \mathrm{H}$ NMR data: $J(3,4)=10.5 \mathrm{~Hz}$. Reaction of 9 with diethyl chlorophosphite in the presence of Hünig's base furnished the desired sialyl donor 2; the structural assignment was confirmed by the ${ }^{1} \mathrm{H}$ NMR data: $J(3,4)=J(4,5)=10.2 \mathrm{~Hz}$.

The transformation of the known GM3 trisaccharide $\mathbf{1 0}^{[15]}$ into the required acceptor 3 could be readily carried out (Scheme 3). Selective removal of the $O$-acetyl protecting

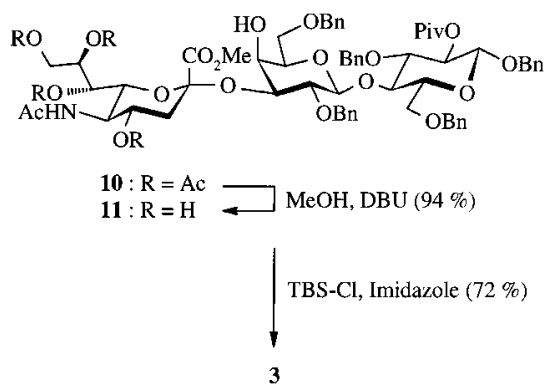

Scheme 3 .

group of $\mathbf{1 0}$ was performed in methanol at $-20^{\circ} \mathrm{C}$ in the presence of a catalytic amount of 1,7-diazabicyclo[5.4.0]undec-7-ene (DBU) to afford compound $\mathbf{1 1}$ in almost quantitative yield. Treatment of $\mathbf{1 1}$ with tert-butyldimethylsilyl chloride (TBS-Cl) in the presence of imidazole led to regioselective $4 \mathrm{c}, 9 \mathrm{c}-O$-silylation, thus providing 3 in $72 \%$ yield. Because of the generally observed low reactivity of the 4-hydroxy group of galactose and the 7-hydroxy group of Neu5Ac residues in sialylation reactions, protection of the $4 \mathrm{~b}$ - and 7c-hydroxy groups was not required.

Sialylation of acceptor $\mathbf{3}$ with donor $\mathbf{2}$ was performed in acetonitrile ${ }^{[15,19]}$ at $-25^{\circ} \mathrm{C}$ in the presence of 0.1 equivalent of TMSOTf as catalyst giving the desired tetrasaccharide $\mathbf{1 2}$ in $54 \%$ yield (Scheme 4 ). Removal of the 3d-phenylthio group was achieved by treatment with tributyltin hydride and activation with azoisobutironitrile (AIBN) to afford compound 13. Reaction with tetrabutylammonium fluoride (TBAF) in $\mathrm{THF}$ at $-20^{\circ} \mathrm{C}$ in the presence of acetic acid led 


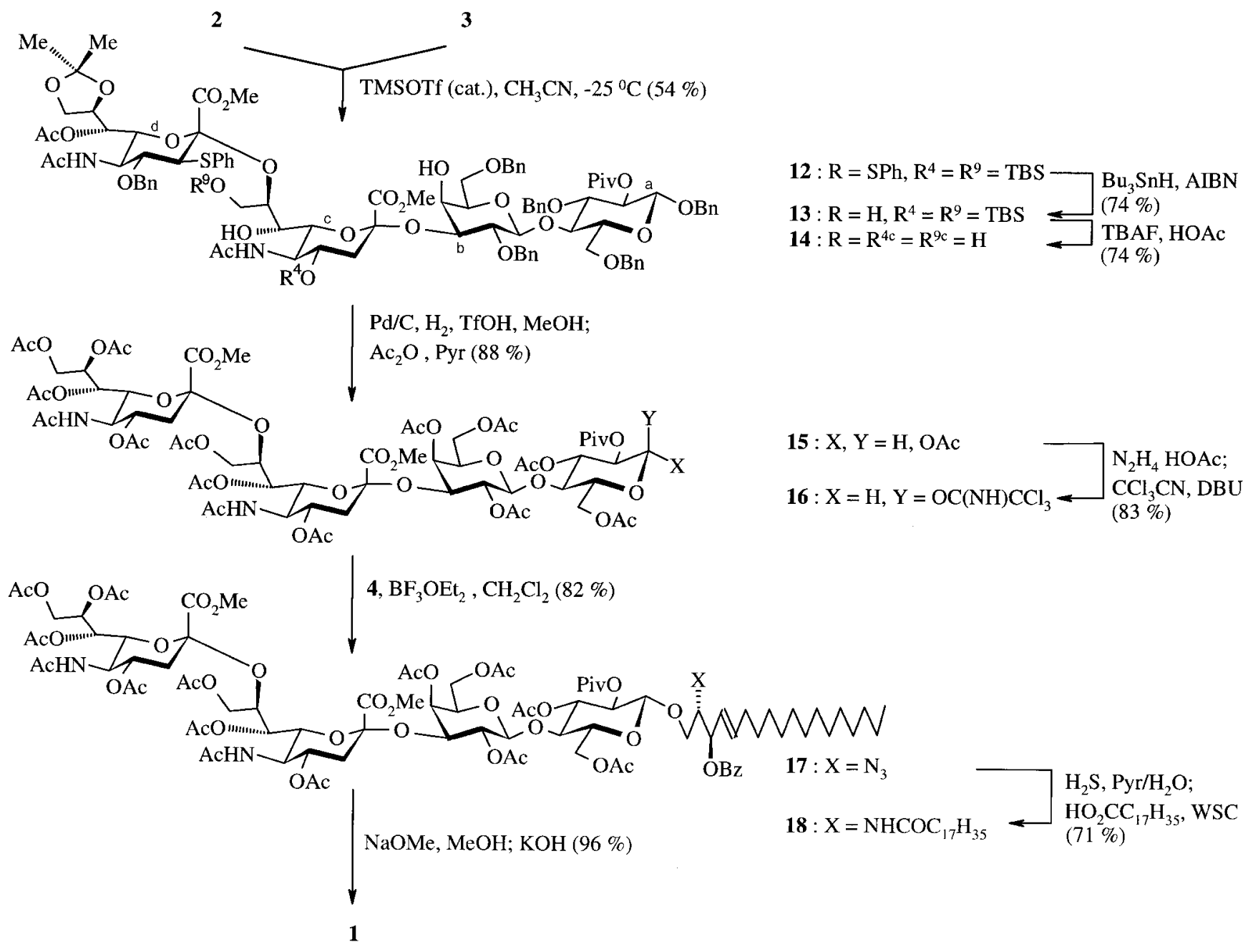

Scheme 4

to the desilylated compound 14. Hydrogenolysis in methanol with palladium on carbon as catalyst and $\mathrm{TfOH}$ as promoter led to $O$-debenzylation with concomitant removal of the $8 \mathrm{~d}, 9 \mathrm{~d}-O$-isopropylidene group. Reaction of the crude product with acetic anhydride in pyridine furnished $O$-acyl-protected tetrasaccharide 15. Regioselective $1 \mathrm{a}-\mathrm{O}$-deacetylation of $\mathbf{1 5}$ with hydrazinium acetate ${ }^{[20]}$ and ensuing treatment with trichloroacetonitrile in the presence of DBU as base afforded trichloroacetimidate 16. Only the $\alpha$-isomer was isolated in $83 \%$ yield.

For the attachment of the ceramide residue, the azidosphingosine glycosylation procedure was employed. ${ }^{[16]}$ To this end, the known 3-O-benzoyl-azidosphingosine $4^{[17]}$ was treated with tetrasaccharide donor $\mathbf{1 6}$ in the presence of borontrifluoride diethyl ether as promoter; this afforded the desired $\beta$ linked glycoside 17 in high yield $\left({ }^{1} \mathrm{H}\right.$ NMR: $\left.J(1 \mathrm{a}, 2 \mathrm{a})=8.8 \mathrm{~Hz}\right)$. Transformation of the azido group into the amino group was performed by treatment with hydrogen sulfide in aqueous pyridine. The crude product was immediately treated with stearic acid and water soluble carbodiimide (WSC) as condensing agent to afford fully $O$-acylated GD3 (18) in $74 \%$ yield. De- $O$-acylation was performed under Zemplén conditions $^{[21]}$ and the methyl ester was cleaved with potassium hydroxide. Ion exchange with Amberlite IR-120 ( $\mathrm{H}^{+}$form $)$ and then RP-18 column chromatography afforded pure GD3 (1) which had optical rotation and NMR data in accordance with those previously reported. ${ }^{[10,12,22]}$

\section{GD3-triggered uncoupling of mitochondrial respiration:} Gangliosides, especially disialoganglioside GD3, have recently been implicated in the signalling of apoptosis. ${ }^{[4]}$ Although the mechanisms involved have not been completely elucidated yet, the triggering of mitochondrial permeability transition (PT) appears to be a key event. ${ }^{[5]} \mathrm{PT}$ is characterised by a loss of the permeability barrier of the inner mitochondrial membrane to molecules $>1500 \mathrm{Da}$ and it can be specifically inhibited by the cyclophilin ligand cyclosporine A. ${ }^{[23]}$ PTdependent effects of GD3 on mitochondrial function, such as the uncoupling of respiration have been demonstrated directly with the isolated organelles. ${ }^{[5,24]}$ We used this wellcharacterised in vitro system for an initial comparison of synthetic and bovine-brain (BB) GD3. The uncouplinginduced increase in mitochondrial respiration after exposure of rat-liver mitochondria to synthetic and BB GD3 was measured in an oxygraph. Synthetic and BB GD3 showed a similar concentration dependency with respect to the uncoupling of mitochondria (Figure 1a), while the control ganglio- 

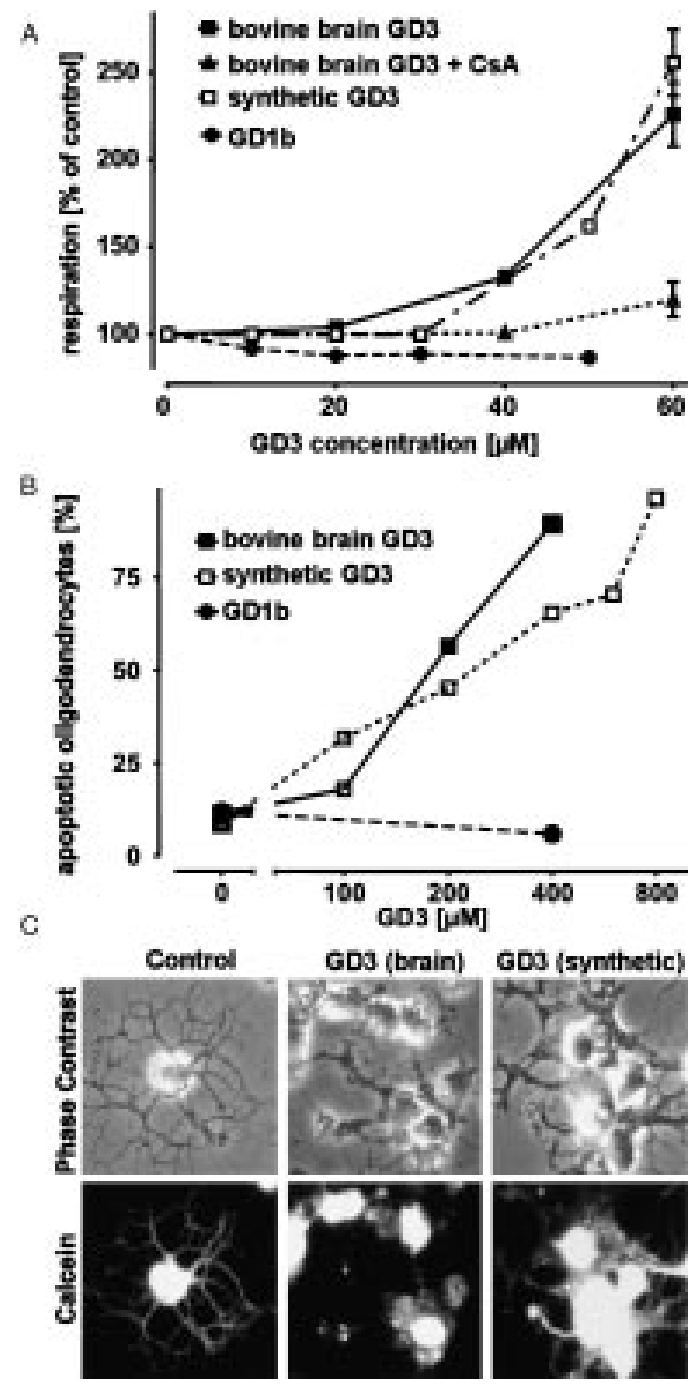

Figure 1. Biological studies. A: Isolated rat-liver mitochondria were incubated in an oxygraph chamber. Initial respiration was set to $100 \%$. Increasing respiration due to the uncoupling effect of GD3 was measured. The specificity of the effect was controlled by blocking with cyclosporine A (CsA, 2 mm) or adding of a noneffective control ganglioside (GD1b). Data are means of two experiments with $\mathrm{SD}<10 \%$. B: Murine oligodendrocytes were incubated for $24 \mathrm{~h}$ with different concentrations of either synthetic GD3 or GD3 extracted from bovine brains. Cells were then fixed and stained for the oligodendrocyte marker protein cyclic nucleotide $2^{\prime}, 3^{\prime}$ phosphodiesterase (CNPase). Nuclei were stained with the DNA dye H-33342. Apoptotic oligodendrocytes were scored by counting CNPasepositive cells that showed alterations in nuclear morphology, as indicated by chromatin condensation. Data are averaged from six experiments in three different cell preparations. C: Murine oligodendrocytes were incubated for $24 \mathrm{~h}$ with $400 \mathrm{~mm}$ of either synthetic GD3 or bovine brain extracted GD3. Cells were then stained with $1 \mathrm{~mm}$ calcein-acetoxymethylester (AM), a dye that fluoresces when it is accumulated in vital cells. Phase contrast images and the corresponding images from the calcein staining are shown.

side GD1b did not show this effect. Uncoupling of mitochondria may be due to contaminating lipophilic protonophores present in either GD3 preparation. Such an effect would not be subject to inhibition by cyclosporine A. However, the complete prevention of GD3-induced mitochondrial changes in the presence of cyclosporine A indicates a specific effect of both synthetic and BB GD3, mediated by PT. Conversely, cyclosporine A did not prevent increased respiration after exposure to the nonspecific protonophore uncoupler FCCP within the same system (not shown).

Comparison of GD3 preparations with respect to induction of apoptosis in oligodendrocytes: GD3 has been shown to trigger apoptotic death in various cell types. We chose oligodendrocytes, the most sensitive cell population in the brain, ${ }^{[25]}$ to compare the effects of synthetic and BB GD3. Both preparations induced a similar degeneration of cellular processes later followed by apoptotic chromatin condensation (Figure 1b). Also, both preparations triggered a defined sequence of degenerative events different from a potential nonspecific detergent effect. This is exemplified by the intactness of the plasma membrane (retention of calcein) $24 \mathrm{~h}$ after exposure to GD3, a time point when the chromatin shows features of apoptotic condensation (Figure 1c). Specificity is further indicated by the finding that the related ganglioside GD1b did not cause death in oligodendrocytes. An exact concentration-response comparison of the two preparations showed that slightly higher concentrations of synthetic GD3 were required for a given apoptotic effect (Figure 1b). This may be due the different composition of fatty acid residues in synthetic and BB GD3. While all fatty acid residues of synthetic GD3 have the same length $\left(\mathrm{C}_{18}\right)$, a mixture of fatty acids forms the lipophilic moiety of BB GD3. The formation of micelles is favoured for this reason in the synthetic GD3. The potential re-formation of micelles after sonication of GD3 and the start of the incubation in the medium had more pronounced effects in the cell culture experiments that extended over $24 \mathrm{~h}$ than in the experiments with isolated mitochondria that were terminated after $30 \mathrm{~min}$.

\section{Conclusion}

Sialyl donor 2 can be readily obtained from the known 2,3dehydroneuraminic acid derivative $\mathbf{5}$. Donor $\mathbf{2}$ is highly reactive. With the GM3-derived acceptor $\mathbf{3}$, it afforded the desired $\alpha(2-8)$-linkage between two neuraminic acid residues in good yield, thus finally affording, via trisaccharide 12, GD3 in good overall yield ( 8 steps, $13 \%$ ). Intermediate 12 should also be an ideal precursor for further chain extension with sialyl donor 2. ${ }^{[26]}$ It is clearly shown that damage of oligodendrocytes from mouse brain and respiration of mitochondria from rat liver cells are dependent on the concentration of the GD3 thus obtained.

\section{Experimental Section}

General techniques: Solvents were purified according to standard procedures. Flash chromatography was performed on Baker silica gel 60 (0.040 $0.063 \mathrm{~mm}$ ) at a pressure of 0.4 bar. Thin-layer chromatography was performed on Merck silica gel plastic plates $60 \mathrm{~F}_{254}$; compounds were visualised by treatment with a solution of $\left(\mathrm{NH}_{4}\right)_{6} \mathrm{Mo}_{7} \mathrm{O}_{24} \cdot 4 \mathrm{H}_{2} \mathrm{O}(20 \mathrm{~g})$ and $\mathrm{Ce}\left(\mathrm{SO}_{4}\right)_{2}(0.4 \mathrm{~g})$ in $10 \%$ sulfuric acid $(400 \mathrm{~mL})$ and heating at $150{ }^{\circ} \mathrm{C}$. Optical rotations were measured on a Perkin-Elmer 241 polarimeter in a $1 \mathrm{dm}$ cell at $22^{\circ} \mathrm{C}$. NMR measurements were recorded at $22^{\circ} \mathrm{C}$ on a Bruker AC250 Cryospec or a BrukerDRX600 apparatus. TMS or the 
resonance of the deuterated solvent was used as an internal standard; solvents: $\mathrm{CDCl}_{3}, \delta=7.24 ; \mathrm{CD}_{3} \mathrm{OD}, \delta=3.31$.

Methyl 5-Acetamido-2,3,5-trideoxy-D-glycero-D-galacto-non-2-enopyranosonate (5): Compound $\mathbf{5}$ was synthesised following a published procedure. ${ }^{[18]}$

Methyl 5-Acetamido-2,3,5-trideoxy-8,9-O-isopropylidene-D-glycero-Dgalacto-non-2-enopyranosonate (6): Triflic acid $(30 \mu \mathrm{L})$ was added to a suspension of $5(5 \mathrm{~g}, 164 \mathrm{mmol})$ in dry acetone $(30 \mathrm{~mL})$ and the mixture was stirred for $3 \mathrm{~h}$ at room temperature until a clear solution was obtained. The solution was then neutralised with $\mathrm{Et}_{3} \mathrm{~N}$ and concentrated to give 6 ( $5.2 \mathrm{~g}$, quant.). The physical data are in accordance with published values. ${ }^{[14]}$

Methyl 5-Acetamido-4-O-benzyl-2,3,5-trideoxy-8,9-O-isopropylidene-Dglycero-D-galacto-non-2-enopyranosonate (7): A solution of $6(2 \mathrm{~g}$, $5.8 \mathrm{mmol})$ and benzyl bromide $(0.9 \mathrm{~mL}, 7.5 \mathrm{mmol})$ in DMF $(10 \mathrm{~mL})$ was cooled to $0^{\circ} \mathrm{C}$. Sodium hydride $(185 \mathrm{mg}, 7.6 \mathrm{mmol})$ was then added over a period of $30 \mathrm{~min}$ at $0^{\circ} \mathrm{C}$. The reaction was stirred for another $10 \mathrm{~min}$ at $0{ }^{\circ} \mathrm{C}$, then methanol $(0.1 \mathrm{~mL})$ was added, and the mixture was evaporated in vacuo. The residue was dissolved in dichloromethane $(15 \mathrm{~mL})$, washed with water $(2 \times 5 \mathrm{~mL})$, dried $\left(\mathrm{MgSO}_{4}\right)$, filtered and concentrated. The desired compound 7 crystallised from hexane/ethyl acetate (15:1). Yield: $2.5 \mathrm{~g}$, $83 \%$; m.p. $144^{\circ} \mathrm{C} ;[\alpha]_{\mathrm{D}}=+10\left(c=0.5, \mathrm{CHCl}_{3}\right) ;{ }^{1} \mathrm{H}$ NMR $(600 \mathrm{MHz}$, $\left.\mathrm{CDCl}_{3}\right): \delta=1.27,1.30(2 \mathrm{~s}, 6 \mathrm{H} ; 2 \mathrm{Me}$-isopropyl), 1.92 (s, $3 \mathrm{H} ; \mathrm{NCOMe}), 3.45$ $(\mathrm{dd}, 1 \mathrm{H}, J(6,7)=2.88 \mathrm{~Hz}, J(7,8)=8.16 \mathrm{~Hz} ; 7 \mathrm{H}), 3.72(\mathrm{~s}, 3 \mathrm{H} ;$ COOMe $)$, 3.98 (m, 2 H; H6, H9), 4.11 (m, 2 H; H9', H4), 4.18 (m, 1 H; H5), 4.26 (m, $1 \mathrm{H} ; \mathrm{H} 8), 4.52\left(\mathrm{~m}, 2 \mathrm{H} ; \mathrm{CH}_{2} \mathrm{Ph}\right), 5.25(\mathrm{~d}, 1 \mathrm{H}, J(\mathrm{NH}, 5)=9.5 \mathrm{~Hz} ; \mathrm{NH}), 6.02$ $(\mathrm{d}, 1 \mathrm{H}, J(3,4)=2.88 \mathrm{~Hz} ; \mathrm{H} 3), 7.29(\mathrm{~m}, 5 \mathrm{H}, \mathrm{Ph})$; elemental analysis calcd (\%) for $\mathrm{C}_{22} \mathrm{H}_{29} \mathrm{NO}_{8}$ (435.6): $\mathrm{C} 60.68, \mathrm{H} 6.66, \mathrm{~N} 3.21$; found $\mathrm{C} 60.71, \mathrm{H} 6.67, \mathrm{~N}$ 3.14

Methyl 5-Acetamido-4-O-benzyl-3-bromo-3,5-dideoxy-8,9- $O$-isopropylidene- $\boldsymbol{\beta}$-D-erythro-L-manno-2-nonulopyranosonate (8): Acetic anhydride $(5 \mathrm{~mL})$ was added to a solution of $7(2 \mathrm{~g}, 3.5 \mathrm{mmol})$ in pyridine $(10 \mathrm{~mL})$. The solution was stirred for $2 \mathrm{~h}$, then concentrated. A solution of the residue in acetonitrile/water $(6: 1,14 \mathrm{~mL})$ was heated at $60^{\circ} \mathrm{C} . \mathrm{N}$ Bromosuccinimide $(0.8 \mathrm{~g}, 3.7 \mathrm{mmol})$ was then added, and the solution was stirred at $60{ }^{\circ} \mathrm{C}$ for $10 \mathrm{~min}$, then allowed to reach room temperature. Solvents were evaporated and the residue was purified by column chromatography (toluene/acetone 4:1) to afford 8. Yield: $1.85 \mathrm{~g}, 71 \%$; $[\alpha]_{\mathrm{D}}=+24\left(c=1, \mathrm{CHCl}_{3}\right) ;{ }^{1} \mathrm{H} \mathrm{NMR}\left(600 \mathrm{MHz}, \mathrm{CDCl}_{3}\right): \delta=1.34,1.35(2 \mathrm{~s}$, $6 \mathrm{H} ; 2 \mathrm{Me}$-isopropyl), 1.98 (s, 3 H; NCOMe), 2.18 (s, 3 H; OCOMe), 3,51 (m, $1 \mathrm{H} ; \mathrm{H} 9), 3.75$ (s, 3 H; COOMe), 4.08 (m, $\left.1 \mathrm{H} ; \mathrm{H}^{\prime}\right), 4.52\left(\mathrm{~m}, 2 \mathrm{H} ; \mathrm{CH}_{2} \mathrm{Ph}\right)$, $4.71(\mathrm{~m}, 2 \mathrm{H} ; \mathrm{H} 6, \mathrm{H} 3), 5.28(\mathrm{dd}, 1 \mathrm{H}, J(6,7)=2.88 \mathrm{~Hz}, J(7,8)=8.16 \mathrm{~Hz} ; \mathrm{H} 7)$, $5.70(\mathrm{brs}, 1 \mathrm{H} ; \mathrm{OH}), 5.82(\mathrm{~d}, 1 \mathrm{H}, J(\mathrm{NH}, 5)=9.8 \mathrm{~Hz} ; \mathrm{NH}), 7.44(\mathrm{~m}, 5 \mathrm{H}, \mathrm{Ph})$; elemental analysis calcd (\%) for $\mathrm{C}_{24} \mathrm{H}_{32} \mathrm{BrNO}_{10}$ (574.4): C 50.17, $\mathrm{H} \mathrm{5.57,} \mathrm{N}$ 2.44; found C 50.11, H 5.46, N 2.34.

Methyl 5-Acetamido-4- $O$-benzyl-3,5-dideoxy-8,9- $O$-isopropylidene-3-phenylthio- $\beta$-D-erythro-L-gluco-2-nonulopyranosonate (9): Sodium thiophenolate $(0.5 \mathrm{~g}, 3.7 \mathrm{mmol})$ was added to a solution of $\mathbf{8}(2 \mathrm{~g}, 3.7 \mathrm{mmol})$ in dry THF $(15 \mathrm{~mL})$, and the mixture was stirred for $20 \mathrm{~min}$, then concentrated. Column chromatography of the residue (toluene/acetone 3:1) afforded 9. Yield: $2.3 \mathrm{~g}, 92 \% ;[\alpha]_{\mathrm{D}}=+14\left(c=1, \mathrm{CHCl}_{3}\right) ;{ }^{1} \mathrm{H} \mathrm{NMR}\left(600 \mathrm{MHz}, \mathrm{CDCl}_{3}\right)$ : $\delta=1.32,1.33(2 \mathrm{~s}, 6 \mathrm{H} ; 2 \mathrm{Me}$-isopropyl), 1.82 (s, 3H; NCOMe), $2.10(\mathrm{~s}, 3 \mathrm{H}$; OCOMe), 3.60 (s, 3 H; COOMe), 3.63 (d, $1 \mathrm{H} ; \mathrm{J}(3,4)=10.5 \mathrm{~Hz}, \mathrm{H} 3), 3.80$ $4.28\left(\mathrm{~m}, 4 \mathrm{H} ; \mathrm{H} 9, \mathrm{H} 9^{\prime}, \mathrm{H} 4, \mathrm{H} 5\right), 4.42(\mathrm{dd}, 1 \mathrm{H}, J(5,6)=8.2 \mathrm{~Hz}, J(6,7)=$ $2.1 \mathrm{~Hz} ; \mathrm{H} 6), 4.78\left(\mathrm{~m}, 2 \mathrm{H} ; \mathrm{CH}_{2} \mathrm{Ph}\right), 5.05(\mathrm{brs}, 1 \mathrm{H} ; \mathrm{OH}), 5.34(\mathrm{dd}, 1 \mathrm{H}$, $J(6,7)=2.12 \mathrm{~Hz}, J(7,8)=8.10 \mathrm{~Hz} ; \mathrm{H} 7), 5.80(\mathrm{~d}, 1 \mathrm{H}, J(\mathrm{NH}, 5)=9.8 \mathrm{~Hz}$; $\mathrm{NH}), 7.10-7.50(\mathrm{~m}, 10 \mathrm{H}, 2 \mathrm{Ph})$; elemental analysis calcd $(\%)$ for $\mathrm{C}_{30} \mathrm{H}_{37} \mathrm{NO}_{10} \mathrm{~S}$ (603.8): C 59.68, H 6.13, N 2.32; found C 59.76, H 6.18, N 2.34.

Methyl 5-Acetamido-4- $O$-benzyl-3,5-dideoxy-8,9- $O$-isopropylidene-3-phenylthio- $\beta$-D-erythro-L-gluco-2-nonulopyranosonate-diethylphosphite (2): Ethyldiisopropylamine $(0.8 \mathrm{~mL}, 4.6 \mathrm{mmol})$ and diethylchlorophosphite $(0.6 \mathrm{~mL}, 3.9 \mathrm{mmol})$ were added to a solution of $9(2 \mathrm{~g}, 3.31 \mathrm{mmol})$ in dry acetonitrile $(15 \mathrm{~mL})$. The solution was stirred for $30 \mathrm{~min}$ at room temperature, then concentrated. Column chromatography of the residue on silica gel (toluene/acetone 4:1) gave $\mathbf{2}$ as a pale yellow syrup. Yield: $2.1 \mathrm{~g}, 92 \%$; $[\alpha]_{\mathrm{D}}=+22\left(c=1, \mathrm{CHCl}_{3}\right) ;{ }^{1} \mathrm{H} \mathrm{NMR}\left(250 \mathrm{MHz}, \mathrm{CDCl}_{3}\right): \delta=1.28-1.41(\mathrm{~m}$, $12 \mathrm{H}$; $2 \mathrm{Me}$-isopropyl, $2 \mathrm{Me}$ ), 1.82 (s, 3 H; NCOMe), 2.12 (s, $3 \mathrm{H}$; OCOMe), $3.52(\mathrm{~d}, 1 \mathrm{H} ; J(3,4)=10.5 \mathrm{~Hz}, \mathrm{H} 3), 3.58(\mathrm{~s}, 3 \mathrm{H} ; \mathrm{COOMe}) 3.78-4.20(\mathrm{~m}$, $7 \mathrm{H} ; 2 \mathrm{CH}_{2}, \mathrm{H} 9, \mathrm{H} 9$ ', H5), 4.32(dd, $1 \mathrm{H}, J(3,4)=10.5 \mathrm{~Hz}, J(4,5)=10.5 \mathrm{~Hz}$, $\mathrm{H} 4), 4.42(\mathrm{dd}, 1 \mathrm{H}, J(5,6)=8.2 \mathrm{~Hz}, J(6,7)=2.1 \mathrm{~Hz} ; \mathrm{H} 6), 4.76(\mathrm{~m}, 2 \mathrm{H}$; $\left.\mathrm{CH}_{2} \mathrm{Ph}\right), 5.42$ (m, 2H; NH, H7), 7.10-7.50 (m, 10 H, 2Ph).
Glucopyranoside 10: Compound $\mathbf{1 0}$ was synthesised following a published procedure. The physical data are in accordance with published values. ${ }^{[15]}$

Glucopyranoside 11: A solution of the known trisaccharide $10(2 \mathrm{~g}$, $1.46 \mathrm{mmol})$ in dry methanol $(30 \mathrm{~mL})$ was cooled to $-20^{\circ} \mathrm{C}$ and $\mathrm{DBU}$ $(30 \mu \mathrm{L})$ was added. The solution was stirred for $4 \mathrm{~h}$ at $-20^{\circ} \mathrm{C}$, then neutralised $\left(\mathrm{H}^{+}\right.$-Amberlite), filtered and concentrated. Column chromatography of the residue (chloroform/acetone 8:1) afforded 11. Yield: $1.6 \mathrm{~g}$, $94 \% ;[\alpha]_{\mathrm{D}}=-8\left(c=0.5, \mathrm{CHCl}_{3}\right) ;{ }^{1} \mathrm{H}$ NMR $\left(250 \mathrm{MHz}, \mathrm{CD}_{3} \mathrm{OD}\right): \delta=1.15$ (s, 3H; OPiv), 1.96 (s, 3H; NCOMe), $2.10(\mathrm{dd}, 1 \mathrm{H}, J(\mathrm{gem})=13.0 \mathrm{~Hz}$, $\left.J(3 \mathrm{ax}, 4)=12.3 \mathrm{~Hz} ; 3 \mathrm{c}_{\mathrm{ax}}-\mathrm{H}\right), 2.58(\mathrm{dd}, 1 \mathrm{H}, J(\mathrm{gem})=13.0 \mathrm{~Hz}, J(3 \mathrm{eq}, 4)=$ $\left.4.6 \mathrm{~Hz} ; 3 \mathrm{c}_{\mathrm{eq}}-\mathrm{H}\right), 3.33$ (m, 1 H; H5a), 3.36 (s, 3 H; COOMe), 3.57-3.72 (m, 6 H; H3a, H5b, H9c, H9'c, H8c, H7c), $3.77-3.87$ (m, 2 H; H6a, H2b), $3.95-$ 4.15 (m, 8H; H6'a, H6b, H6'b, H4c, H5c, H6c, NH, H4b), 4.30-4.46 (m, $\left.4 \mathrm{H} ; \mathrm{H} 4 \mathrm{a}, \mathrm{H} 3 \mathrm{~b}, \mathrm{CH}_{2} \mathrm{Ph}\right), 4.48(\mathrm{~d}, 1 \mathrm{H}, J(1 \mathrm{a}, 2 \mathrm{a})=8.0 \mathrm{~Hz} ; \mathrm{H} 1 \mathrm{a}), 4.48-5.02$ $\left(\mathrm{m}, 9 \mathrm{H} ; 4 \mathrm{CH}_{2} \mathrm{Ph}, \mathrm{H} 1 \mathrm{~b}\right), 5.05(\mathrm{dd}, 1 \mathrm{H}, J(1 \mathrm{a}, 2 \mathrm{a})=8.0 \mathrm{~Hz}, J(2 \mathrm{a}, 3 \mathrm{a})=8.0 \mathrm{~Hz}$ $\mathrm{H} 2 \mathrm{a}), 7.10-7.69(\mathrm{~m}, 30 \mathrm{H} ; 6 \mathrm{Ph})$; elemental analysis calcd $(\%)$ for $\mathrm{C}_{64} \mathrm{H}_{79} \mathrm{NO}_{20}$ (1181.2): C 65.01, H 6.68, N 1.18; found C 65.11, H 6.67, N 1.14.

Glucopyranoside (3): tert-Butyldimethylsilyl chloride $(0.7 \mathrm{~g}, 3.74 \mathrm{mmol})$ and imidazole $(0.31 \mathrm{~g}, 3.82 \mathrm{mmol})$ were added to a solution of $\mathbf{1 1}(2 \mathrm{~g}$, $1.7 \mathrm{mmol})$ in dry dichloromethane $(20 \mathrm{~mL})$. The mixture was stirred for $8 \mathrm{~h}$ at room temperature, then filtered and concentrated. Column chromatography (toluene/acetone $3: 1$ ) of the residue gave $\mathbf{3}$ as a white foam. Yield: $1.81 \mathrm{~g}, 72 \% ;[\alpha]_{\mathrm{D}}=-15\left(c=0.5, \mathrm{CHCl}_{3}\right) ;{ }^{1} \mathrm{H}$ NMR $\left(250 \mathrm{MHz}, \mathrm{CDCl}_{3}\right): \delta=$ $0.10,0.11,0.13,0.14(4 \mathrm{~s}, 12 \mathrm{H} ; 4 \mathrm{SiMe}), 0.86,0.89(2 \mathrm{~s}, 6 \mathrm{H} ; 2 t \mathrm{Bu}), 1.16(\mathrm{~s}$ $3 \mathrm{H}$; OPiv), 1.96 (s, 3H; NCOMe), $2.10(\mathrm{dd}, 1 \mathrm{H}, J(\mathrm{gem})=13.0 \mathrm{~Hz}$, $\left.J(3 \mathrm{ax}, 4)=12.3 \mathrm{~Hz} ; 3 \mathrm{c}_{\mathrm{ax}}-\mathrm{H}\right), 2.58(\mathrm{dd}, 1 \mathrm{H}, J(\mathrm{gem})=13.0 \mathrm{~Hz}, J(3 \mathrm{eq}, 4)=$ $\left.4.6 \mathrm{~Hz} ; 3 \mathrm{c}_{\mathrm{eq}}-\mathrm{H}\right), 3.33$ (m, 1 H; H5a), 3.36 (s, 3 H; COOMe), 3.57-3.72 (m, 6 H; H3a, H5b, H9c, H9'c, H8c, H7c), $3.77-3.87$ (m, 2 H; H6a, H2b), $3.95-$ 4.15 (m, 8H; H6'a, H6b, H6'b, H4c, H5c, H6c, NH, H4b), 4.30-4.46 (m, $\left.4 \mathrm{H} ; \mathrm{H} 4 \mathrm{a}, \mathrm{H} 3 \mathrm{~b}, \mathrm{CH}_{2} \mathrm{Ph}\right), 4.48(\mathrm{~d}, 1 \mathrm{H}, J(1 \mathrm{a}, 2 \mathrm{a})=8.0 \mathrm{~Hz} ; \mathrm{H} 1 \mathrm{a}), 4.48-5.02$ $\left(\mathrm{m}, 9 \mathrm{H} ; 4 \mathrm{CH}_{2} \mathrm{Ph}, \mathrm{H} 1 \mathrm{~b}\right), 5.00(\mathrm{dd}, 1 \mathrm{H}, J(1 \mathrm{a}, 2 \mathrm{a})=8.0 \mathrm{~Hz}, J(2 \mathrm{a}, 3 \mathrm{a})=8.0 \mathrm{~Hz}$ $\mathrm{H} 2 \mathrm{a}), 7.10-7.69(\mathrm{~m}, 30 \mathrm{H} ; 6 \mathrm{Ph})$; elemental analysis calcd $(\%)$ for $\mathrm{C}_{76} \mathrm{H}_{107} \mathrm{NO}_{20} \mathrm{Si}$ (1409.1): C 64.72, H 7.59, N 0.99; found C 64.61, H 7.57, N 0.95 .

Glucopyranoside 12: A solution of trisaccharide acceptor $3(500 \mathrm{mg}$, $0.34 \mathrm{mmol})$ and the phosphite donor $2(370 \mathrm{mg}, 0.5 \mathrm{mmol})$ in dry acetonitrile $(15 \mathrm{~mL})$ was cooled to $-25^{\circ} \mathrm{C}$. Trimethylsilyl trifluoromethanesulfonate $(9 \mu \mathrm{L}, 0.05 \mathrm{mmol})$ was then added and the solution was stirred for $2 \mathrm{~h}$ at $-25^{\circ} \mathrm{C}$, then allowed to reach room temperature. The solution was neutralised with $\mathrm{Et}_{3} \mathrm{~N}$ and concentrated. Column chromatography of the residue (toluene/acetone 3.5:1) afforded 12. Yield: $410 \mathrm{mg}, 54 \%$; $[\alpha]_{\mathrm{D}}=-11\left(c=1, \mathrm{CHCl}_{3}\right) ;{ }^{1} \mathrm{H} \mathrm{NMR}\left(600 \mathrm{MHz}, \mathrm{CDCl}_{3}\right): \delta=0.10,0.11$, 0.13, 0.14 (4s, 12 H; $4 \mathrm{SiMe}), 0.86,0.89$ (2s, $18 \mathrm{H} ; 2 t \mathrm{Bu}), 1.16$ (s, $3 \mathrm{H}$; OPiv), 1.32, 1.33 (2s, 6 H; 2 Me-isopropyl), 1.86,1.96 (2s, 6 H; 2 NCOMe), 2.05 (dd, $\left.1 \mathrm{H}, J(\mathrm{gem})=13.0 \mathrm{~Hz}, J(3 \mathrm{ax}, 4)=12.3 \mathrm{~Hz} ; 3 \mathrm{c}_{\mathrm{ax}}-\mathrm{H}\right), 2.10(\mathrm{~s}, 3 \mathrm{H}$; OCOMe $)$, $2.58\left(\mathrm{dd}, 1 \mathrm{H}, J(\mathrm{gem})=13.0 \mathrm{~Hz}, J(3 \mathrm{eq}, 4)=4.6 \mathrm{~Hz} ; 3 \mathrm{c}_{\mathrm{eq}}-\mathrm{H}\right), 3.33(\mathrm{~m}, 1 \mathrm{H}$; H5a), 3.36 (s, 3H; COOMe), 3.54 (s, 3H; COOMe), 3.57-3.72 (m, 7H H3a, H5b, H9c, H9'c, H8c, H7c, H3d), 3.77-3.87 (m, 4 H; H6a, H2b, H9d, H9'd), 3.95 - 4.15 (m, 10 H; H6'a, H6b, H6'b, H4c, H5c, H6c, NH, H4b, H4d H5d), 4.30-4.46 (m, 5 H; H4a, H3b, $\left.\mathrm{CH}_{2} \mathrm{Ph}, \mathrm{H} 6 \mathrm{~d}\right), 4.48$ (d, 1 H, J(1a,2a) = $8.0 \mathrm{~Hz}$; H1a), $4.48-5.02\left(\mathrm{~m}, 11 \mathrm{H} ; 5 \mathrm{CH}_{2} \mathrm{Ph}, \mathrm{H} 1 \mathrm{~b}\right), 5.10(\mathrm{dd}, 1 \mathrm{H}, J(1 \mathrm{a}, 2 \mathrm{a})=$ $8.0 \mathrm{~Hz}, J(2 \mathrm{a}, 3 \mathrm{a})=8.0 \mathrm{~Hz} ; \mathrm{H} 2 \mathrm{a}), 5.34(\mathrm{dd}, 1 \mathrm{H}, J(6,7)=2.12 \mathrm{~Hz}, J(7,8)=$ $8.10 \mathrm{~Hz}$; H7d), 5.42 (m, 2H, 2NH), 7.10-7.69 (m, 40 H; 8Ph); elemental analysis calcd (\%) for $\mathrm{C}_{106} \mathrm{H}_{143} \mathrm{~N}_{2} \mathrm{O}_{29} \mathrm{SSi}$ (1995.2): C 63.75, H 7.16, N 1.40; found $\mathrm{C} 63.71, \mathrm{H} 7.23, \mathrm{~N} 1.44$.

Glucopyranoside 13: Tributylstannane $(0.18 \mathrm{~mL}, 0.7 \mathrm{mmol})$ and AIBN $(20 \mathrm{mg})$ were added to a solution of $\mathbf{1 2}(400 \mathrm{mg}, 0.2 \mathrm{mmol})$ in toluene $(10 \mathrm{~mL})$ under an argon atmosphere. The mixture was heated at $120^{\circ} \mathrm{C}$ for $3 \mathrm{~h}$, still under an argon atmosphere, then concentrated. Column chromatography of the residue (toluene/acetone 3:1) afforded 13. Yield: $274 \mathrm{mg}$, $74 \% ;[\alpha]_{\mathrm{D}}=-22\left(c=1, \mathrm{CHCl}_{3}\right) ;{ }^{1} \mathrm{H}$ NMR $\left(600 \mathrm{MHz}, \mathrm{CDCl}_{3}\right): \delta=0.10$, $0.11,0.13,0.14(4 \mathrm{~s}, 12 \mathrm{H} ; 4 \mathrm{SiMe}), 0.86,0.89(2 \mathrm{~s}, 18 \mathrm{H} ; 2 t \mathrm{Bu}), 1.18(\mathrm{~s}, 3 \mathrm{H}$; OPiv), 1.32, 1.33 (2s, 6H; 2 Me-isopropyl), 1.86,1.96 (2s, 6H; 2NCOMe), $2.05\left(\mathrm{~m}, 2 \mathrm{H} ; 3 \mathrm{c}_{\mathrm{ax}}-\mathrm{H}, 3 \mathrm{~d}_{\mathrm{ax}}-\mathrm{H}\right), 2.12\left(\mathrm{~s}, 3 \mathrm{H} ;\right.$ OCOMe), $2.56\left(\mathrm{~m}, 2 \mathrm{H} ; 3 \mathrm{c}_{\mathrm{eq}}-\mathrm{H}\right.$, $\left.3 \mathrm{~d}_{\mathrm{eq}}-\mathrm{H}\right), 3.35$ (m, 1 H; H5a), 3.37 (s, 3 H; COOMe), 3.55 (s, 3 H; COOMe), $3.57-3.72$ (m, 6H; H3a, H5b, H9c, H9'c, H8c, H7c), $3.77-3.87$ (m, 4H H6a, H2b, H9d, H9'd), 3.95-4.15 (m, 10H; H6'a, H6b, H6'b, H4c, H5c, H6c, NH, H4b, H4d, H5d), 4.30-4.46 (m, 5H; H4a, H3b, $\mathrm{CH}_{2} \mathrm{Ph}, \mathrm{H} 6 \mathrm{~d}$ ), $4.48(\mathrm{~d}, 1 \mathrm{H}, \mathrm{J}(1 \mathrm{a}, 2 \mathrm{a})=8.0 \mathrm{~Hz} ; \mathrm{H} 1 \mathrm{a}), 4.48-5.02\left(\mathrm{~m}, 11 \mathrm{H} ; 5 \mathrm{CH}_{2} \mathrm{Ph}, \mathrm{H} 1 \mathrm{~b}\right)$, $5.10(\mathrm{dd}, 1 \mathrm{H}, J(1 \mathrm{a}, 2 \mathrm{a})=8.0 \mathrm{~Hz}, J(2 \mathrm{a}, 3 \mathrm{a})=8.0 \mathrm{~Hz} ; \mathrm{H} 2 \mathrm{a}), 5.34(\mathrm{dd}, 1 \mathrm{H}$, $J(6,7)=2.12 \mathrm{~Hz}, J(7,8)=8.10 \mathrm{~Hz}$; H7d), $5.42(\mathrm{~m}, 2 \mathrm{H}, 2 \mathrm{NH}), 7.10-7.69$ (m, 
$35 \mathrm{H} ; 7 \mathrm{Ph}$ ); elemental analysis calcd (\%) for $\mathrm{C}_{100} \mathrm{H}_{138} \mathrm{~N}_{2} \mathrm{O}_{29} \mathrm{Si}$ (1886.1): C 63.62, H 7.31, N 1.48; found C 63.51, H 7.32, N 1.45.

Glucopyranoside 14: Acetic acid $(10 \mu \mathrm{L})$ and TBAF (1M solution in THF, $0.4 \mathrm{~mL})$ were added to a solution of $\mathbf{1 3}(200 \mathrm{mg}, 0.1 \mathrm{mmol})$ in dry $\mathrm{THF}$ $(3 \mathrm{~mL})$ at $-20^{\circ} \mathrm{C}$. The reaction was stirred for $6 \mathrm{~h}$ at $-20^{\circ} \mathrm{C}$, then acetic acid $(1 \mathrm{~mL})$ was added, and the solution was concentrated. Column chromatography of the residue (toluene/acetone 1:1) afforded $\mathbf{1 4}$ as a white foam. Yield: $125 \mathrm{mg}, 74 \% ;[\alpha]_{\mathrm{D}}=-18\left(c=1, \mathrm{CHCl}_{3}\right) ;{ }^{1} \mathrm{H} \mathrm{NMR}\left(600 \mathrm{MHz}, \mathrm{CDCl}_{3}\right): \delta=$ 1.18 (s, 3H; OPiv), 1.32, $1.33(2 \mathrm{~s}, 6 \mathrm{H} ; 2 \mathrm{Me}$-isopropyl), 1.86, $1.96(2 \mathrm{~s}, 6 \mathrm{H}$; $2 \mathrm{NCOMe}$ ), $2.05\left(\mathrm{~m}, 2 \mathrm{H} ; 3 \mathrm{c}_{\mathrm{ax}}-\mathrm{H}, 3 \mathrm{~d}_{\mathrm{ax}}-\mathrm{H}\right), 2.12$ (s, 3 H; OCOMe), $2.56(\mathrm{~m}$, $\left.2 \mathrm{H} ; 3 \mathrm{c}_{\mathrm{eq}}-\mathrm{H}, 3 \mathrm{~d}_{\mathrm{eq}}-\mathrm{H}\right), 3.35$ (m, $1 \mathrm{H}$; H5a), 3.37 (s, 3 H; COOMe), 3.55 (s, $3 \mathrm{H}$; COOMe), 3.57 - 3.72 (m, 6 H; H3a, H5b, H9c, H9'c, H8c, H7c), 3.77-3.87 (m, 4H; H6a, H2b, H9d, H9'd), $3.95-4.15$ (m, 10 H; H6'a, H6b, H6'b, H4c, H5c, H6c, NH, H4b, H4d, H5d), 4.30-4.46 (m, 5H; H4a, H3b, $\mathrm{CH}_{2} \mathrm{Ph}$, H6d), $4.48(\mathrm{~d}, 1 \mathrm{H}, J(1 \mathrm{a}, 2 \mathrm{a})=8.0 \mathrm{~Hz} ; \mathrm{H1a}), 4.48-5.02\left(\mathrm{~m}, 11 \mathrm{H} ; 5 \mathrm{CH}_{2} \mathrm{Ph}\right.$, $\mathrm{H} 1 \mathrm{~b}), 5.10(\mathrm{dd}, 1 \mathrm{H}, J(1 \mathrm{a}, 2 \mathrm{a})=8.0 \mathrm{~Hz}, J(2 \mathrm{a}, 3 \mathrm{a})=8.0 \mathrm{~Hz} ; \mathrm{H} 2 \mathrm{a}), 5.34(\mathrm{dd}$, $1 \mathrm{H}, J(6,7)=2.12 \mathrm{~Hz}, J(7,8)=8.10 \mathrm{~Hz} ; \mathrm{H} 7 \mathrm{~d}), 5.48(\mathrm{~m}, 2 \mathrm{H}, 2 \mathrm{NH}), 7.10-7.69$ $(\mathrm{m}, 35 \mathrm{H} ; 7 \mathrm{Ph})$; elemental analysis calcd (\%) for $\mathrm{C}_{88} \mathrm{H}_{108} \mathrm{~N}_{2} \mathrm{O}_{29} \mathrm{~S}(1656.2)$ : $\mathrm{C}$ 63.76, H 6.52, N 1.69; found C 63.72, H 6.25, N 1.64

Glucopyranose 15: A solution of $\mathbf{1 4}(160 \mathrm{mg}, 0.1 \mathrm{mmol})$ in methanol $(10 \mathrm{~mL})$ and triflic acid $(2 \mu \mathrm{L})$ was hydrogenated in the presence of $10 \%$ $\mathrm{PdC}(50 \mathrm{mg})$ for $12 \mathrm{~h}$ at room temperature, then filtered and concentrated. The residue was treated with acetic anhydride $(1 \mathrm{~mL})$, pyridine $(3 \mathrm{~mL})$ and 4-dimethylaminopyridine $(20 \mathrm{mg})$ for $24 \mathrm{~h}$ at room temperature. The solvents were evaporated and the residue was purified by column chromatography on silica gel (toluene/acetone 5:2) to afford 15. Yield: $123 \mathrm{mg}, 88 \% ;[\alpha]_{\mathrm{D}}=-24\left(c=1, \mathrm{CHCl}_{3}\right) ;{ }^{1} \mathrm{H}$ NMR $\left(600 \mathrm{MHz}, \mathrm{CDCl}_{3}\right): \delta=$ 1.25 (s, 3 H; OPiv), 1.86- $2.20\left(\mathrm{~m}, 47 \mathrm{H} ; 3 \mathrm{c}_{\mathrm{ax}}-\mathrm{H}, 3 \mathrm{~d}_{\mathrm{ax}}-\mathrm{H}, 15 \mathrm{COMe}\right), 2.60(\mathrm{~m}$, $\left.2 \mathrm{H} ; 3 \mathrm{c}_{\mathrm{eq}}-\mathrm{H}, 3 \mathrm{~d}_{\mathrm{eq}}-\mathrm{H}\right), 3.35(\mathrm{~m}, 2 \mathrm{H}$; H5a, H4b), 3.70-4.46 (m, 22 H; H4a, H5a, H6a, H6'a, H3b, H5b, H6b, H6'b, H5c, H6c, H9c, H9'c, H5d, H6d, H9d, H9'd, 2COOMe), 4.50-4.80 (m, 4H; H1b, H4c, H4d, H8c), $4.93-$ 5.24(m, 4H; H2a $\alpha, \mathrm{H} 2 \mathrm{a} \beta, \mathrm{H} 3 \mathrm{a} \alpha, \mathrm{H} 2 \mathrm{~b}, \mathrm{NH}), 5.33-5.54(\mathrm{~m}, 4 \mathrm{H} ; \mathrm{H} 3 \mathrm{a} \alpha, \mathrm{H} 7 \mathrm{c}$, $\mathrm{H} 4 \mathrm{~d}, \mathrm{H} 7 \mathrm{~d}, \mathrm{H} 8 \mathrm{~d}), 5.67(\mathrm{~d}, 1 \mathrm{H}, J(1,2)=8.2 \mathrm{~Hz}$; H1a $\beta), 6.26(\mathrm{~d}, 1 \mathrm{H}, J(1,2)=$ $3.7 \mathrm{~Hz} ; \mathrm{H} 1 \mathrm{a} \alpha$ ); elemental analysis calcd (\%) for $\mathrm{C}_{67} \mathrm{H}_{92} \mathrm{~N}_{2} \mathrm{O}_{41}$ (1580.3): C 50.88, H 5.82, N 1.77; found C 50.81, H 5.73, N 1.74

Trichloroacetimidate 16: A solution of $\mathbf{1 4}(1 \mathrm{~g}, 0.75 \mathrm{mmol})$ and hydrazinium acetate $(101 \mathrm{mg}, 1.10 \mathrm{mmol})$ in dry DMF $(8 \mathrm{~mL})$ was stirred for $20 \mathrm{~min}$ at $40^{\circ} \mathrm{C}$, then diluted with EtOAc $(50 \mathrm{~mL})$, washed with water, with saturated aqueous $\mathrm{NaHCO}_{3}$ solution and then again with water, dried $\left(\mathrm{MgSO}_{4}\right)$ and concentrated. A solution of the residue, trichloroacetonitrile $(1 \mathrm{~mL}, 10 \mathrm{mmol})$ and DBU $(0.15 \mathrm{~mL}, 1 \mathrm{mmol})$ in dichloromethane $(10 \mathrm{~mL})$ was stirred for $45 \mathrm{~min}$ at room temperature, then concentrated. The residue was eluted from a column of silica gel (toluene/acetone 2:1 containing $0.1 \%$ of $\mathrm{Et}_{3} \mathrm{~N}$ ) to afforded 16 as a white foam. Yield: $0.95 \mathrm{~g}, 83 \% ;[\alpha]_{\mathrm{D}}=$ $+8\left(c=0.8, \mathrm{CHCl}_{3}\right) ;{ }^{1} \mathrm{H}$ NMR $\left(600 \mathrm{MHz}, \mathrm{CDCl}_{3}\right): \delta=1.30$ (s, $3 \mathrm{H} ;$ OPiv), 1.86- $2.20\left(\mathrm{~m}, 44 \mathrm{H} ; 3 \mathrm{c}_{\mathrm{ax}}-\mathrm{H}, 3 \mathrm{~d}_{\mathrm{ax}}-\mathrm{H}, 14 \mathrm{COMe}\right), 2.60\left(\mathrm{~m}, 2 \mathrm{H} ; 3 \mathrm{c}_{\mathrm{eq}}-\mathrm{H}, 3 \mathrm{~d}_{\mathrm{eq}}\right.$ H), 3.35 (m, 2H; H5a, H4b), 3.70-4.46 (m, 22 H; H4a, H5a, H6a, H6'a, H3b, H5b, H6b, H6'b, H5c, H6c, H9c, H9'c, H5d, H6d, H9d, H9'd, 2 COOMe), $4.50-4.80$ (m, 4H; H1b, H4c, H4d, H8c), $4.93-5.24$ (m, 3 H; H2a, H2b, NH), 5.33 - 5.54 (m, 4 H; H3a, H7c, H4d, H7d, H8d), 6.43 (d, 1 H, $J(1,2)=3.2 \mathrm{~Hz}, \mathrm{H} 1 \mathrm{a}), 8.63(\mathrm{~s}, 1 \mathrm{H}, \mathrm{NH})$

(2S,3 R,4 E)-2-Azido-3-O-benzoyl-4-octadecene-1,3-diol (4): Compound 4 was synthesised following a published procedure. ${ }^{[17]}$

Diol 17: A solution of $4(68 \mathrm{mg}, 0.16 \mathrm{mmol})$ and borontrifluoride etherate $(20 \mu \mathrm{L}, 0.16 \mathrm{mmol})$ in dry dichloromethane $(2 \mathrm{~mL})$ was cooled to $0^{\circ} \mathrm{C}$. A solution of the imidate $\mathbf{1 6}(118 \mathrm{mg}, 0.08 \mathrm{mmol})$ in dry dichloromethane $(1 \mathrm{~mL})$ was added dropwise to this solution under a nitrogen atmosphere. After $1 \mathrm{~h}$ the solution was neutralised with triethylamine and evaporated in vacuo. The residue was purified by flash chromatography (toluene/acetone $2: 1)$ to afford 17. Yield: $118 \mathrm{mg}, 82 \% ;[\alpha]_{\mathrm{D}}=+13\left(c=0.8, \mathrm{CHCl}_{3}\right)$; ${ }^{1} \mathrm{H}$ NMR $\left(600 \mathrm{MHz}, \mathrm{CDCl}_{3}\right): \delta=0.86\left(\mathrm{t}, 3 \mathrm{H} ; \mathrm{MeCH}_{2}\right), 1.16(\mathrm{~s}, 9 \mathrm{H} ; \mathrm{OPiv})$, $1.24\left(\mathrm{~m}, 22 \mathrm{H} ; 11 \mathrm{CH}_{2}\right), 1.86-2.20\left(\mathrm{~m}, 46 \mathrm{H} ; 3 \mathrm{c}_{\mathrm{ax}}-\mathrm{H}, 3 \mathrm{~d}_{\mathrm{ax}}-\mathrm{H}, \mathrm{CH}_{2}, 14 \mathrm{COMe}\right)$, 2.68 (m, 2 H; 3c $\left.\mathrm{c}_{\mathrm{eq}}-\mathrm{H}, 3 \mathrm{~d}_{\mathrm{eq}}-\mathrm{H}\right), 3.35$ (m, 2 H; H5a, H4b), 3.38(m, 1 H, H2d), 3.60 - 4.46 (m, 24 H; H4a, H5a, H6a, H6'a, H3b, H5b, H6b, H6’b, H5c, H6c, H9c, H9'c, H5d, H6d, H9d, H9'd, 2 COOMe, $\left.\mathrm{OCH}_{2} \mathrm{R}\right), 4.50-4.80$ (m, 4H; $\mathrm{H} 1 \mathrm{~b}, \mathrm{H} 4 \mathrm{c}, \mathrm{H} 4 \mathrm{~d}, \mathrm{H} 8 \mathrm{c}), 4.94$ (d, $1 \mathrm{H}, J(1,2)=8.8 \mathrm{~Hz}$; H1a), 4.96-5.24 (m, $3 \mathrm{H} ; \mathrm{H} 2 \mathrm{a}, \mathrm{H} 2 \mathrm{~b}, \mathrm{NH}), 5.33-5.54(\mathrm{~m}, 4 \mathrm{H} ; \mathrm{H} 3 \mathrm{a}, \mathrm{H} 7 \mathrm{c}, \mathrm{H} 4 \mathrm{~d}, \mathrm{H} 7 \mathrm{~d}, \mathrm{H} 8 \mathrm{~d}$, $\mathrm{CHOBz}, \mathrm{CH}=\mathrm{CHR}), 5.84(\mathrm{~m}, 1 \mathrm{H} ; \mathrm{CH}=\mathrm{CHR}), 7.40-8.00(\mathrm{~m}, 5 \mathrm{H} ; \mathrm{OBz})$; elemental analysis calcd (\%) for $\mathrm{C}_{90} \mathrm{H}_{127} \mathrm{~N}_{5} \mathrm{O}_{42}$ (1949.2): C 55.41, H 6.51, N 3.59 ; found C 55.32, H 6.63, N 3.64 .
Diol 18: Hydrogen sulfide was bubbled through a stirred solution of $\mathbf{1 7}$ $(102 \mathrm{mg}, 0.06 \mathrm{mmol})$ in aqueous $83 \%$ pyridine $(5 \mathrm{~mL})$ for $48 \mathrm{~h}$ at $0{ }^{\circ} \mathrm{C}$. The reaction was monitored by TLC. After completion of the reaction, the mixture was concentrated, and the residue was stirred with octadecanoic acid (39 mg, $0.12 \mathrm{mmol}$ ) and 1-ethyl-3-(3-dimethylaminopropyl)carbodiimide hydrochloride $(39 \mathrm{mg}, 0.18 \mathrm{mmol})$ in dry dichloromethane $(5 \mathrm{~mL})$ for $12 \mathrm{~h}$ at room temperature. Column chromatography of the residue (toluene/acetone 2:1) on silica gel gave $\mathbf{1 8}$ as an amorphous mass. Yield: $126 \mathrm{mg}, 74 \% ;[\alpha]_{\mathrm{D}}=+8\left(c=0.8, \mathrm{CHCl}_{3}\right) ;{ }^{1} \mathrm{H} \mathrm{NMR}\left(600 \mathrm{MHz}, \mathrm{CDCl}_{3}\right)$ : $\delta=0.88\left(\mathrm{~m}, 6 \mathrm{H} ; 2 \mathrm{MeCH}_{2}\right), 1.18(\mathrm{~s}, 9 \mathrm{H}$; OPiv $), 1.24\left(\mathrm{~m}, 54 \mathrm{H} ; 27 \mathrm{CH}_{2}\right), 1.86-$ $2.20\left(\mathrm{~m}, 46 \mathrm{H} ; 3 \mathrm{c}_{\mathrm{ax}}-\mathrm{H}, 3 \mathrm{~d}_{\mathrm{ax}}-\mathrm{H}, \mathrm{CH}_{2}, 14 \mathrm{COMe}\right), 2.68\left(\mathrm{~m}, 3 \mathrm{H} ; 3 \mathrm{c}_{\mathrm{eq}}-\mathrm{H}, 3 \mathrm{~d}_{\mathrm{eq}}-\mathrm{H}\right.$, $\left.\mathrm{CH}_{2} \mathrm{CON}\right), 3.35$ (m, 2H; H5a, H4b), 3.38(m, $\left.1 \mathrm{H}, \mathrm{H} 2 \mathrm{~d}\right), 3.60-4.46(\mathrm{~m}, 24 \mathrm{H}$; H4a, H5a, H6a, H6'a, H3b, H5b, H6b, H6'b, H5c, H6c, H9c, H9'c, H5d, H6d, H9d, H9'd, 2 COOMe, $\mathrm{OCH}_{2} \mathrm{R}$ ), 4.50-4.80 (m, 4 H; H1b, H4c, H4d, $\mathrm{H} 8 \mathrm{c}), 4.93$ (d, 1 H, J(1,2)=8.8 Hz; H1a), 4.96-5.24 (m, 2H; H2a, H2b, NH), $5.33-5.54$ (m, 4 H; H3a, H7c, H4d, H7d, H8d, CHOBz, CH=CHR), $5.86(\mathrm{~m}, 1 \mathrm{H} ; \mathrm{CH}=\mathrm{CHR}), 7.40-8.00(\mathrm{~m}, 5 \mathrm{H} ; \mathrm{OBz})$; elemental analysis calcd (\%) for $\mathrm{C}_{108} \mathrm{H}_{163} \mathrm{~N}_{3} \mathrm{O}_{43}$ (2189.1): C 59.20, H 7.44, N 1.92; found C 59.11, H 7.43, N 1.85 .

Ganglioside GD3 (1): Sodium methoxide $(20 \mathrm{mg})$ was added to a solution of $\mathbf{1 8}(120 \mathrm{mg})$ in methanol $(5 \mathrm{~mL})$ and the mixture was stirred for $24 \mathrm{~h}$ at room temperature. A solution of potassium hydroxide $(0.2 \mathrm{M}, 1 \mathrm{~mL})$ in methanol was then added and the solution was stirred for another $24 \mathrm{~h}$ at room temperature, neutralised with Amberlite IR-120 $\left(\mathrm{H}^{+}\right)$resin and filtered, the resin was washed with chloroform/methanol (1:1), and the combined filtrate and washings were concentrated. Column chromatography (methanol/water 1:1-6:1) of the residue on RP-18 column gave $\mathbf{1}$ as an amorphous mass. Yield: $82 \mathrm{mg}, 96 \% ;[\alpha]_{\mathrm{D}}=-3\left(c=1, \mathrm{CHCl}_{3}-\mathrm{MeOH}\right.$, $1: 1) ;[\alpha]_{\mathrm{D}}=-2.6\left(c=\mathrm{CHCl}_{3}-\mathrm{MeOH} ;{ }^{[12]}{ }^{1} \mathrm{H}\right.$ NMR $(600 \mathrm{MHz}, \mathrm{MeOH}$, $\left.40^{\circ} \mathrm{C}\right): \delta=0.79\left(\mathrm{~m}, 6 \mathrm{H} ; 2 \mathrm{CH}_{3} \mathrm{CH}_{2}\right), 1.18\left(\mathrm{~s}, 52 \mathrm{H} ; 26 \mathrm{CH}_{2}\right), 1.93,1.95(2 \mathrm{~s}$, $6 \mathrm{H} ; 2 \mathrm{NCOMe}), 2.08\left(\mathrm{t}, 2 \mathrm{H} ; \mathrm{COCH}_{2}\right), 2.48\left(\mathrm{~m}, 2 \mathrm{H} ; \mathrm{H}_{3} \mathrm{c}_{\mathrm{ax}}, \mathrm{H} 3 \mathrm{~d}_{\mathrm{ax}}\right), 2.85(\mathrm{~m}$,

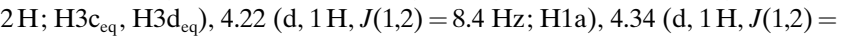
$7.9 \mathrm{~Hz}$; H1b), 5.35 (m, $1 \mathrm{H} ; \mathrm{CH}=\mathrm{CHR}), 5.75(\mathrm{~m}, 1 \mathrm{H} ; \mathrm{CH}=\mathrm{CHR})$. The ${ }^{1} \mathrm{H}$ NMR data are in accordance with those published previously. ${ }^{[10,12,22]}$

Mitochondrial respiration: Mitochondria were isolated from three-monthold rats. ${ }^{[27]}$ Livers were homogenised in ice-cold isolation buffer A [250 mM sucrose, $10 \mathrm{~mm}$ Hepes ( $N$-2-Hydroxyethylpiperazine- $N$ '-2-ethanesulfonic acid), pH 7.4, $1 \mathrm{~mm}$ glutathione (GSH), $1 \mathrm{~mm}$ ethyleneglycol bis(2-aminoethylether)tetraacetic acid (EGTA), 1\% bovine serum albumin (BSA)]. The homogenate was centrifuged for $10 \mathrm{~min}$ at $700 \times \mathrm{g}$ and the supernatant was recentrifuged for $10 \mathrm{~min}$ at $1000 \times \mathrm{g}$. After resuspending the pellets in isolation buffer $\mathrm{B}(125 \mathrm{~mm} \mathrm{KCl}, 10 \mathrm{~mm}$ Hepes, $\mathrm{pH} 7.4,1 \mathrm{~mm} \mathrm{GSH}, 0.1 \mathrm{~mm}$ EGTA), they were centrifuged for $10 \mathrm{~min}$ at $700 \times \mathrm{g}$. The supernatant was recentrifuged for $10 \mathrm{~min}$ at $1000 \times \mathrm{g}$ and the resultant pellet was used as mitochondrial fraction. Isolated rat-liver mitochondria (protein concentration $0.4 \mathrm{mg} \mathrm{mL}^{-1}$ ) were incubated in a medium containing $125 \mathrm{~mm} \mathrm{KCl}$, $10 \mathrm{~mm}$ Hepes, $1 \mathrm{~mm}$, GSH, $2 \mu \mathrm{m}$ rotenone, $5 \mathrm{~mm} \mathrm{Mg}^{2+}$-phosphate, $5 \mathrm{~mm}$ succinate, $\mathrm{pH}$ 7.2. Oxygen consumption was measured at $25^{\circ} \mathrm{C}$ in oxygraphs (Geiger and Para, Innsbruck, Austria) equipped with thermostatic control and magnetic stirrers. GD3 from bovine brain (Sigma, Deisenhofen, Germany) or synthetic GD3 was added to mitochondria after intense sonication in a buffer. The increase of respiration due to uncoupling effects of GD3 was measured as described. ${ }^{[5]}$ Mitochondrial function was controlled at the end of every experiment by adding $100 \mathrm{~nm}$ carbonylcyanide- $p$ (trifluoromethoxy)phenyl hydrazone (FCCP) to stimulate maximal respiration rate. The initial oxygen consumption of mitochondria energised with succinate $\left(31+55.6 \mathrm{nmol} \mathrm{O}_{2}\right.$ per min per mg of protein) was used as the $100 \%$ reference value.

Oligodendrocyte culture: Mouse oligodendrocytes were isolated from a primary mixed brain culture ${ }^{[28]}$ prepared from the brains of BALB/c murine embryos at day 15 after gestation. Oligodendrocyte precursors were shaken off from the astrocyte monolayer at 15 to 20 days after preparation and maintained in Dulbeccos Modified Eagle Medium (Life Technologies, Grand Island, NY) supplemented with $10 \mathrm{ng} \mathrm{mL}^{-1}$ biotin, $100 \mu \mathrm{g} \mathrm{mL}^{-1} \mathrm{BSA}$ and $1 \%$ foetal calf serum. Fresh medium was mixed 1:1 with medium preconditioned by astrocytes for $24 \mathrm{~h}$. Four days after seeding, oligodendrocytes were stimulated with GD3. After $24 \mathrm{~h}$, cells were fixed with paraformaldehyde (PFA, $4 \%$, dissolved in phosphate buffered saline) and immunostained for the oligodendrocyte marker $2^{\prime} 3^{\prime}$ cyclic nucleotide phosphodiesterase (CNPase). , Cells were briefly permeabilised with $0.1 \%$ Triton $\mathrm{X}-100$, incubated for $45 \mathrm{~min}$ with a murine monoclonal antibody 
against CNPase (1:150, Sigma, Deisenhofen, Germany) that had been incubated for $30 \mathrm{~min}$ with a goat-antimouse antibody coupled to Alexa-488 (Molecular Probes, Eugene, OR), stained for DNA with H-33342 (Roche Biochemicals, Mannheim, Germany) and mounted in Aquapolymount (Polysciences, Warrington, PA, USA). The number of oligodendrocytes with changed nuclear morphology was scored by counting six microscopic fields for each experimental condition by using a fluorescent microscope (DM IRBIL, Leica Mikroskopie und Systeme GmbH, Wetzlar, Germany).

\section{Acknowledgements}

This work was supported by the Deutsche Forschungsgemeinschaft and the research focus "Endogenous tissue destruction We686/18". We are grateful for the technical help by Elvira Gawlitta-Gorka.

[1] R. Schauer, Sialic Acids, Chemistry, Metabolism and Function, Springer, Vienna, 1982.

[2] a) C. S. Pukel, K. O. Lloyd, L. R. Travassos, W. G. Dippold, H. F Oettgen, L. J. Old, J. Exp. Med. 1982, 155, 1133-1147; b) E. Nudelman, S. Hakomori, R. Kannagi, S. Levery, M.-Y. Yeh, K. E. Hellström, I. Hellström, J. Biol. Chem. 1982, 257, $12752-12756$.

[3] a) S. Zhang, F. Helling, K. O. Lloyd, P. O. Livingston, Cancer Immunol. Immunother. 1995, 40, 88-94; b) W. B. Hamilton, F Helling, K. O. Lloyd, P. O. Livingston, Int. J. Cancer 1993, 53, 566573.

[4] R. De Maria, L. Lenti, F. Malisan, F. d'Agostino, B. Tomassin, A. Zenner, M. R. Rippo, R. Testi, Science 1997, 277, 1652-1655.

[5] a) L. Scorrano, V. Petronilli, F. Dilisa, P. Bernardi, J. Biol. Chem. 1999, 274, 22581-22585; b) C. Garcia-Ruiz, A. Colell, R. Paris, J. C. Fernandez-Checa, FASEB J. 2000, 14, $847-858$

[6] N. Miyatani, M. Saito, T. Ariga, H. Yoshino, R. K. Yu, Mol. Chem. Neuropathol. 1991, 13, 205-215.

[7] F. Malisan, M. R. Rippo, R. De Maria, R. Testi, Results Probl. Cell Differ. 1999, 23, 65-76.

[8] J. C. Castro-Palomino, Y. E. Tsvetkov, R. R. Schmidt, J. Am. Chem. Soc. 1998, 120, 5434-5440, and references therein.

[9] Y. Ito, M. Numata, M. Sugimoto, T. Ogawa, J. Am. Chem. Soc. 1989, $111,8508-8510$.
[10] a) T. Kondo, T. Tomoo, H. Abe, M. Isobe, T.Goto, Chemistry Lett. 1996, 337-338; b) J. Carbohydr. Chem. 1996, 15, 857-878.

[11] N. Hossian, G. Magnusson, Tetrahedron Lett. 1999, 40, 2217-2220.

[12] a) H. Ishida, Y. Ohta, Y. Tsukada, M. Kiso, A. Hasegawa, Carbohydr. Res. 1993, 246, 75-78; b) A. Hasegawa, H. Ishida, M. Kiso, J. Carbohydr. Chem. 1993, 12, 371-376.

[13] a) Y. E. Tsvetkov, R. R. Schmidt, Tetrahedron Lett. 1994, 35, 8583 8586; b) Carbohydr. Lett. 1996, 2, 149-156.

[14] a) J. C. Castro-Palomino, Y. E. Tsvetkov, R. Schneider, R. R. Schmidt, Tetrahedron Lett. 1997, 38, 6837-6840; b) R. R. Schmidt, J. C. CastroPalomino, O. Retz, Pure Appl. Chem. 1999, 71, 729-744.

[15] a) T. J. Martin, R. Brescello, A. Toepfer, R. R. Schmidt, Glycocojugate J. 1993, 10, 16-25; b) J. C. Castro-Palomino, G. Ritter, S. R. Fortunato, S. Reinhardt, L. J. Old, R. R. Schmidt; Angew. Chem. 1997, 109, 2081-2085; Angew. Chem. Int. Ed. Engl. 1997, 36, 234-238, and references therein.

[16] R. R. Schmidt, P. Zimmermann, Angew. Chem. 1986, 98, 722-723; Angew. Chem. Int. Ed. Engl. 1986, 25, $725-726$.

[17] a) R. R. Schmidt, P. Zimmermann, Tetrahedron Lett. 1986, 27, 481 484; b) P. Zimmermann, R. Bommer, T. Bär, R. R. Schmidt, J. Carbohydr. Chem. 1988, 7, 435-452.

[18] G. B. Kok, B. L. Mackey, M. von Itzstein, Carbohydr. Res. 1996, 289, $67-75$.

[19] a) R. R. Schmidt, E. Rücker, Tetrahedron Lett. 1980, 21, 1421 -1424; b) R. R. Schmidt, J. Michel, J. Carbohydr. Chem. 1985, 4, 141-169; c) R. R. Schmidt, M. N. Behrendt, A. Toepfer, Synlett 1990, 694-696.

[20] G. Excoffier, D. Gagnaire, J.-P. Utille, Carbohydr. Res. 1975, 39, 368 373.

[21] G. Zemplen, Ber. Dtsch. Chem. Ges. 1927, 60, 1555-1564.

[22] R. K. Yu, T. A. W. Koerner, J. N. Scardale, J. H. Prestegard, Chem. Phys. Lipids 1986, 42, $27-48$.

[23] P. Bernardi, Biochim. Biophys. Acta 1996, 1275, 5-9.

[24] B. Kristal, A. M. Brown, J. Biol. Chem. 1999, 274, 23169-23175.

[25] B. Simon, M. Leist, unpublished results.

[26] A. Ariosa, J. C. Castro- Palomino, R. R. Schmidt, unpublished results.

[27] P. Costantini, V. Petronelli, R. Coloma, P. Bernardi, Toxicology 1995 , 99, $77-88$.

[28] J. Trotter, D. Bitter-Suermann, M. Schachner, J. Neuroscience Res. 1989, 22, 369-383. 